\title{
Plasma fatty acids as diagnostic markers in autistic patients from Saudi Arabia
}

Afaf K El-Ansary ${ }^{1,2,3,4^{*}}$, Abir G Ben Bacha ${ }^{1,2,3}$ and Layla Y Al- Ayahdi ${ }^{1,2,3,5}$

\begin{abstract}
Backgrounds: Autism is a family of developmental disorders of unknown origin. The disorder is characterized by behavioral, developmental, neuropathological and sensory abnormalities, and is usually diagnosed between the ages of 2 and 10 with peak prevalence rates observed in children aged 5-8 years. Recently, there has been heightened interest in the role of plasma free fatty acids (FA) in the pathology of neurological disorders. The aim of this study is to compare plasma fatty acid profiles of Saudi autistic patients with those of age-matching control subjects in an attempt to clarify the role of FA in the etiology of autism.
\end{abstract}

Methods: 26 autistic patients together with 26-age-matching controls were enrolled in the present study. Methyl esters of FA were extracted with hexane, and the fatty acid composition of the extract was analyzed on a gas chromatography.

Results: The obtained data proved that fatty acids are altered in the plasma of autistic patients, specifically showing an increase in most of the saturated fatty acids except for propionic acid, and a decrease in most of polyunsaturated fatty acids. The altered fatty acid profile was discussed in relation to oxidative stress, mitochondrial dysfunction and the high lead $(\mathrm{Pb})$ concentration previously reported in Saudi autistic patients. Statistical analysis of the obtained data shows that most of the measured fatty acids were significantly different in autistic patients compared to age -matching controls.

Conclusions: Receiver Operating Characteristic (ROC) curve analysis shows satisfactory values of area under the curve (AUC) which could reflect the high degree of specificity and sensitivity of the altered fatty acids as biomarkers in autistic patients from Saudi Arabia.

Keywords: Autism Fatty acids, Oxidative stress, Valeric acid, Propionic acid, Polyunsaturated fatty acids

\section{Introduction}

Autism is a developmental disorder characterized by impaired communication and social behavioral features, as well as displays of stereotypical behavior, present in the first 3 years of life [1]. Diagnosis of autism is behavior based, and a single behavior or group of behaviors is able to distinguish autism from other developmental disorders [2]. The pathogenesis of autism is uncertain, but is thought to involve an interaction between multiple susceptibility genes and/or epigenetic effects and/or environmental factors [3-5].

\footnotetext{
* Correspondence: elansary@ksu.edu.sa

${ }^{1}$ Biochemistry Department, Science College, King Saud University, P.O Box 22452, Zip code 11495, Riyadh, Saudi Arabia

Full list of author information is available at the end of the article
}

Lipids are heterogeneous molecules that serve many roles, from providing cell structure to energy storage for cell signaling. The brain is one of the most lipidenriched tissues in the human body. Infants' brains are small and undeveloped at birth and must incorporate fatty acids and cholesterol from circulation to develop properly [6]. Docosahexanoic acid (DHA) in particular is found in high abundance in the phospho- lipids of the brain contributing to membrane structure and function, eicosanoid signaling, and gene expression modulation $[7,8]$. DHA also plays a role in inhibition of neuronal apoptosis and in regulating neuronal excitability through GABA receptors $[9,10]$. Furthermore, there is evidence that developing brains obtain fatty acids transported through the blood, especially DHA [11]. Thus, examining the concentrations and compositions
Ciomed Central 
of plasma fatty acids may prove to be diagnostically important.

Mitochondrial fatty acid oxidation (FAO) deficiencies usually present in the neonate or toddler with hypoketotic hypoglycaemia, metabolic acidosis, mitochondrial dysfunction, hyperammonemia, muscle weakness, cardiomyopathy, seizures, psychomotor delay, developmental regression, behavioral disorders and attention deficit disorder [12-15]. Neonatal presentations are usually severe with poor prognosis and include cardiac arrhythmia and sudden death [16], however in mild phenotypes there may be an initial period of normal development and function before decompensation in association with metabolic stress or immune activation, such as fasting, illness or vaccination [17]. With the exception of cardiac involvement and sudden death, all of the metabolic and developmental abnormalities listed above may occur in autism, and the onset of autism may also be regressive following a period of initially normal infant development. This information initiates our interest to examine the plasma fatty acid profiles in autistic patients compared to age-matched control. This may explain their diagnostic and mechanistic roles in a developmental disorder such as autism.

\section{Material and methods Subjects}

The study protocol followed the ethical guidelines of the most recent Declaration of Helsinki (Edinburgh, 2000). All subjects enrolled in the study (26 autistic patients and 26 age-matched controls) had written informed consent provided by their parents and assented to participate if developmentally able. They were enrolled through the ART Center (Autism Research \& Treatment Center) clinic. The ART Center clinic sample population consisted of children diagnosed on the autism spectrum (ASD). The diagnosis of ASD was confirmed in all subjects using the Autism Diagnostic Interview-Revised (ADI-R) and the Autism Diagnostic Observation Schedule (ADOS) and 3DI (Developmental, dimensional diagnostic interview). The ages of all autistic children who participated were between the ages of 4 and 12 years old. All were simplex cases. All are negative for fragile $x$ gene study. The control group recruited from well baby clinic at king Khaled university hospital with mean age 4-11 years old. Subjects were excluded from the investigation if they had organic aciduria, dysmorphic features, or diagnosis of Fragile $\mathrm{X}$ or other serious neurological (e.g., seizures), psychiatric (e.g., bipolar disorder) or known medical conditions. All participants were screened via parental interview for current and past physical illness. Children with known endocrine, cardiovascular, pulmonary, liver, kidney or other medical disease were excluded from the study. None of the recruited autistic patients were on special diets or alternative treatments.

\section{Samples collection}

Blood samples were collected in the morning following at least 10 hour period of fasting. Plasma was collected using standard clinical practices and stored at $-80^{\circ} \mathrm{C}$ until thawed for analysis.

\section{Fatty acid profiling}

Plasma $(200 \mu \mathrm{l})$ lipids were extracted in the presence of internal standards and FA methylated using $3 \mathrm{~N}$ methanolic HCL in sealed vials under nitrogen and incubated at $100 \mathrm{C}$ for $45 \mathrm{~min}$. The methyl esters of free fatty acids were extracted with hexane, and the fatty acid composition of the extract was analyzed on a gas chromatograph (Helwlett- Packard 5890 series II plus, HP analytical Direct, Wilmington, DE), equipped with a flame ionization detector and a $30 \mathrm{~m} \times 0.25 \mathrm{~mm} \times 0.25 \mu \mathrm{m}$ capillary column(Omegawax 250\# 2-4136, Supelco). The helium gas flow rate was $1.2 \mathrm{ml} / \mathrm{min}$, with a split/flow ratio of 50:1. Oven temperature was held at $205^{\circ} \mathrm{C}$. The injector and detector temperatures were 260 and $262^{\circ} \mathrm{C}$, respectively. Two internal standards, C15:0 and C23:0, were added during analysis. Fatty acids were identified via comparison of retention times with authentic standards [18].

\section{Statistical analysis}

An SPSS computer program was used. Results were expressed as mean \pm S.D. and all statistical comparisons were made by means of independent $\mathrm{t}$-Test with $\mathrm{P} \leq$ 0.001 was considered significant. Reciever Operating Characteristics analysis (ROC) was performed. Area under the curve, cutoff values together with degree of specificity and sensitivity were calculated. ROC curves are constructed by plotting the false positive rate (i.e. 100 -specificity) against the true positive rate (i.e. sensitivity). These have been widely accepted as standard tools for evaluating the performance of diagnostic tests. The AUC is an overall summary of diagnostic accuracy, incorporating both components of accuracy, i.e., sensitivity and specificity, into a single measure. The AUC has been widely used as a quantitative index of the performance of a biomarker in a variety of applied fields; it is a simple and convenient overall measure of diagnostic test $[19,20]$.

\section{Results}

Results are presented in tables 1, 2, 3 \& 4 and figures 1 , 2, \&3. Fatty acids concentrations were calculated as mmoles/L plasma. Values are expressed as mean \pm S.D, $P$ value between all controls and all autistic subjects is reported for each fatty acid and illustrated as a star when $\mathrm{P}<0.001$. 
Table 1 Mean \pm S.D of plasma levels of acetic, valeric, hexanoic and stearidonic saturated fatty acids in autistic patients compared to age- matching controls

\begin{tabular}{|c|c|c|c|c|c|}
\hline Fatty acid & Group & $\mathrm{N}$ & Mean \pm S.D. & Percentage change & $P$ value \\
\hline \multirow[t]{2}{*}{ Acetic } & Control & 26 & $0.558 \pm 0.082$ & 100.00 & 0.000 \\
\hline & Autistic & 26 & $0.972 \pm 0.247$ & 174.14 & \\
\hline \multirow[t]{2}{*}{ Valeric } & Control & 26 & $0.100 \pm 0.015$ & 100.00 & 0.000 \\
\hline & Autistic & 26 & $0.510 \pm 0.229$ & 509.27 & \\
\hline \multirow[t]{2}{*}{ Hexanoic } & Control & 26 & $0.597 \pm 0.478$ & 100.00 & 0.000 \\
\hline & Autistic & 26 & $1.442 \pm 0.349$ & 241.65 & \\
\hline \multirow[t]{2}{*}{ Stearidonic } & Control & 26 & $0.363 \pm 0.122$ & 100.00 & 0.009 \\
\hline & Autistic & 26 & $0.455 \pm 0.120$ & 125.17 & \\
\hline
\end{tabular}

This table describes the independent t-test between the control and autistic groups regarding levels of acetic, valeric, hexanoic and stearidonic acids expressed in $\mathrm{mmol} / \mathrm{L}$ plasma. Significant level at $\mathrm{p}<0.001$

Table 2 Mean \pm S.D of saturated, mono and polyunsaturated fatty acids in plasma of autistic patients compared to controls

\begin{tabular}{|c|c|c|c|c|c|}
\hline Fatty acid & Group & $\mathrm{N}$ & Mean \pm S.D. & Percentage change & $P$ value \\
\hline \multirow[t]{2}{*}{ Propionic } & Control & 26 & $1.674 \pm 0.441$ & 100.00 & 0.000 \\
\hline & Autistic & 26 & $0.874 \pm 0.249$ & 52.23 & \\
\hline \multirow[t]{2}{*}{ Butyric } & Control & 26 & $0.738 \pm 0.211$ & 100.00 & 0.028 \\
\hline & Autistic & 26 & $0.587 \pm 0.267$ & 79.54 & \\
\hline \multirow[t]{2}{*}{ Caprylic } & Control & 26 & $2.250 \pm 0.481$ & 100.00 & 0.000 \\
\hline & Autistic & 26 & $1.109 \pm 0.281$ & 49.31 & \\
\hline \multirow[t]{2}{*}{ Decanoic } & Control & 26 & $1.954 \pm 0.750$ & 100.00 & 0.000 \\
\hline & Autistic & 26 & $0.759 \pm 0.182$ & 38.81 & \\
\hline \multirow[t]{2}{*}{ Lauric } & Control & 26 & $1.903 \pm 0.574$ & 100.00 & 0.000 \\
\hline & Autistic & 26 & $0.808 \pm 0.160$ & 42.45 & \\
\hline \multirow[t]{2}{*}{ Palmitic } & Control & 26 & $1.905 \pm 0.537$ & 100.00 & 0.037 \\
\hline & Autistic & 26 & $1.631 \pm 0.372$ & 85.62 & \\
\hline \multirow[t]{2}{*}{ Stearic } & Control & 26 & $1.219 \pm 0.315$ & 100.00 & 0.000 \\
\hline & Autistic & 26 & $0.687 \pm 0.281$ & 56.36 & \\
\hline \multirow[t]{2}{*}{ Arachidic } & Control & 26 & $0.673 \pm 0.174$ & 100.00 & 0.000 \\
\hline & Autistic & 26 & $0.425 \pm 0.222$ & 63.10 & \\
\hline \multirow[t]{2}{*}{$\alpha$-Linolenic } & Control & 26 & $0.354 \pm 0.119$ & 100.00 & 0.045 \\
\hline & Autistic & 26 & $0.299 \pm 0.067$ & 84.35 & \\
\hline \multirow[t]{2}{*}{ Eicosapentaenoic } & Control & 26 & $0.328 \pm 0.112$ & 100.00 & 0.245 \\
\hline & Autistic & 22 & $0.284 \pm 0.145$ & 86.64 & \\
\hline \multirow[t]{2}{*}{ Docosahexaenoic } & Control & 26 & $0.754 \pm 0.340$ & 100.00 & 0.000 \\
\hline & Autistic & 22 & $0.380 \pm 0.097$ & 50.40 & \\
\hline \multirow[t]{2}{*}{ Linoleic } & Control & 26 & $0.359 \pm 0.162$ & 100.00 & 0.023 \\
\hline & Autistic & 26 & $0.220 \pm 0.255$ & 61.35 & \\
\hline \multirow[t]{2}{*}{$\gamma$-Linolenic } & Control & 26 & $0.716 \pm 0.323$ & 100.00 & 0.000 \\
\hline & Autistic & 20 & $0.162 \pm 0.101$ & 22.59 & \\
\hline \multirow[t]{2}{*}{ Arachidonic } & Control & 26 & $0.574 \pm 0.202$ & 100.00 & 0.000 \\
\hline & Autistic & 20 & $0.120 \pm 0.040$ & 20.89 & \\
\hline \multirow[t]{2}{*}{ Oleic } & Control & 26 & $1.212 \pm 0.518$ & 100.00 & 0.000 \\
\hline & Autistic & 26 & $0.225 \pm 0.064$ & 18.55 & \\
\hline \multirow[t]{2}{*}{ Elaidic } & Control & 26 & $0.234 \pm 0.080$ & 100.00 & 0.000 \\
\hline & Autistic & 26 & $0.122 \pm 0.099$ & 52.28 & \\
\hline
\end{tabular}

This table describes the independent t-test between the control and autistic groups specified saturated, mono and polyunsaturated fatty acids. Fatty acids are expressed in $\mathrm{mmol} / \mathrm{L}$ plasma. Significant level at $\mathrm{p}<0.001$ 
Table 3 Roc analysis - related data of valeric, hexanoic and stearidonic saturated fatty acids

\begin{tabular}{ccccc}
\hline Fatty acid & Area under the curve & Best Cutoff value & Sensitivity $\%$ & Specificity $\%$ \\
\hline Acetic & 0.985 & 0.684 & $92.3 \%$ & $92.3 \%$ \\
\hline Valeric & 1.000 & 0.196 & $100.0 \%$ & $100.0 \%$ \\
\hline Hexanoic & 0.916 & 1.009 & $92.3 \%$ & $88.5 \%$ \\
\hline Stearidonic & 0.734 & 0.344 & $80.8 \%$ & $65.4 \%$ \\
\hline
\end{tabular}

Table 1 and figure 1 demonstrate the elevated plasma levels in autistic patients of the following saturated fatty acids: acetic, valeric, hexanoic and stearidonic. While stearidonic acid shows the least percentage increase (25\%), valeric acid shows highest plasma levels in autistic patients compared to controls (409.27\%). Acetic and hexanoic acids gave 74.14 and $41.65 \%$ increase respectively.

On the other hand, Table 2 demonstrates the reduced levels of different saturated, mono or polyunsaturated fatty acids in autistic patients when compared to control subjects. Figure 2 shows different percentage decrease of saturated (propionic, butyric, caprylic, decanoic, lauric, palmitic and stearic) together with mono (oleic) and polyunsaturated fatty acids. Oleic, arachidonic, $\gamma$-linolenic, decanoic, caprilic and propionic were the most significantly impaired levels recorded percentage decreases of $81.45,79.11,77.41$, $61.14,50.6$ and $47.77 \%$, respectively.

ROC curves are presented in figure $3(\mathrm{a}-\mathrm{k})$. Area under the curve, cutoff values together with degree of specificity and sensitivity are presented in table 3 and 4 respectively. It could be easily noticed that autistic patients have remarkably different fatty acid profiles compared to controls. Most of the measured fatty acids recorded high values of specificity and sensitivity.

\section{Discussion}

Biomarkers should ideally be quantitative biological measures with an accurate indication of a specific mechanism and ideally are not invasive. Identifying biomarkers will almost certainly lead to a better understanding of the pathogenesis required to design the most effective treatments of autism.

The present study recorded high significant alterations in the fatty acid profiles of autistic patients compared to age-matching controls. Table 1 demonstrates levels of certain saturated fatty acids in both groups. It could be easily seen that short chain fatty acids represented by acetic, valeric, hexanoic and stearidonic acids were significantly higher in autistic patients compared to control (table 1 and figure 1). The significantly higher level of acetic acid could be easily related to the gastrointestinal inflammation as one of the most common clinical presentation of autism. It is well known that acetic acid induced colitis is a well -established model [21-23] whereby acetate ions cause massive intracellular

Table 4 Roc analysis - related data of specified saturated, mono and polyunsaturated fatty acids

\begin{tabular}{|c|c|c|c|c|}
\hline Fatty acid & Area under the curve & Best Cutoff value & Sensitivity \% & Specificity $\%$ \\
\hline Propionic & 0.963 & 1.279 & $92.3 \%$ & $84.6 \%$ \\
\hline Butyric & 0.655 & 0.689 & $65.4 \%$ & $50.0 \%$ \\
\hline Caprylic & 0.972 & 1.617 & $100.0 \%$ & $92.3 \%$ \\
\hline Decanoic & 0.996 & 1.197 & $100.0 \%$ & $92.3 \%$ \\
\hline Lauric & 1.000 & 1.214 & $100.0 \%$ & $100.0 \%$ \\
\hline Palmitic & 0.631 & 1.874 & $69.2 \%$ & $46.2 \%$ \\
\hline Stearic & 0.897 & 0.975 & $84.6 \%$ & $84.6 \%$ \\
\hline Arachidic & 0.823 & 0.462 & $76.9 \%$ & $92.3 \%$ \\
\hline a-Linolenic & 0.611 & 0.325 & $69.2 \%$ & $50.0 \%$ \\
\hline Eicosapentaenoic & 0.617 & 0.283 & $54.5 \%$ & $57.7 \%$ \\
\hline Docosahexaenoic & 0.876 & 0.427 & $77.3 \%$ & $84.6 \%$ \\
\hline Linoleic & 0.791 & 0.162 & $76.9 \%$ & $100.0 \%$ \\
\hline Y-Linolenic & 0.996 & 0.338 & $100.0 \%$ & $96.2 \%$ \\
\hline Arachidonic & 1.000 & 0.271 & $100.0 \%$ & $100.0 \%$ \\
\hline Oleic & 1.000 & 0.463 & $100.0 \%$ & $100.0 \%$ \\
\hline Elaidic & 0.831 & 0.213 & $80.8 \%$ & $76.9 \%$ \\
\hline
\end{tabular}




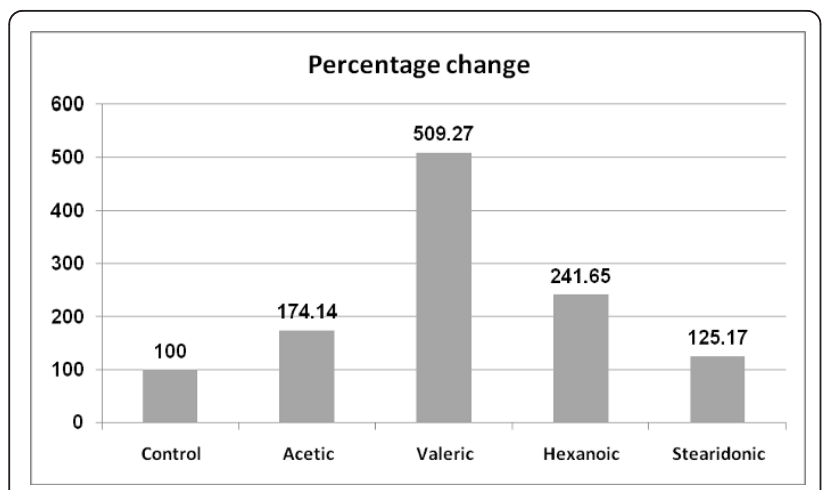

Figure 1 Percentage change in valeric, hexanoic and stearidonic acids of autistic patients $(\mathrm{N}=26)$ compared to control $(\mathrm{N}=26)$.

acidification resulting in injury of epithelial cells and inflammatory response [24].

The most remarkable elevation in fatty acid level in the present study was observed in valeric acid. The extremely high level of valeric acid ( $409.27 \%$ increase) could be related to the increase of $\alpha$-keto $\beta$-methyl valeric acid (KMV) derivative previously reported as an antioxidant highly effective in neutralizing $\mathrm{H}_{2} \mathrm{O}_{2}$ oxidative stress [25]. The authors reported that tissue accumulation and high urinary excretion of KMV occurred in maple syrup urine disease (MSUD) which shows neurological dysfunction. They assessed the effect of KMV on the activities of the mitochondrial respiratory chain complexes in cerebral cortex from young rats in an attempt to elucidate the biochemical defect responsible for the inhibition of aerobic metabolism (lower $\mathrm{CO}_{2}$ formation) and activation of anaerobic glycolysis (increased lactate release). They recorded that KMV inhibited complex I-III of the respiratory chain and significantly stimulated lactate production by around 20-30\%. Therefore, it may be concluded that KMV could alter the energy metabolism in brain cortex. In addition, the

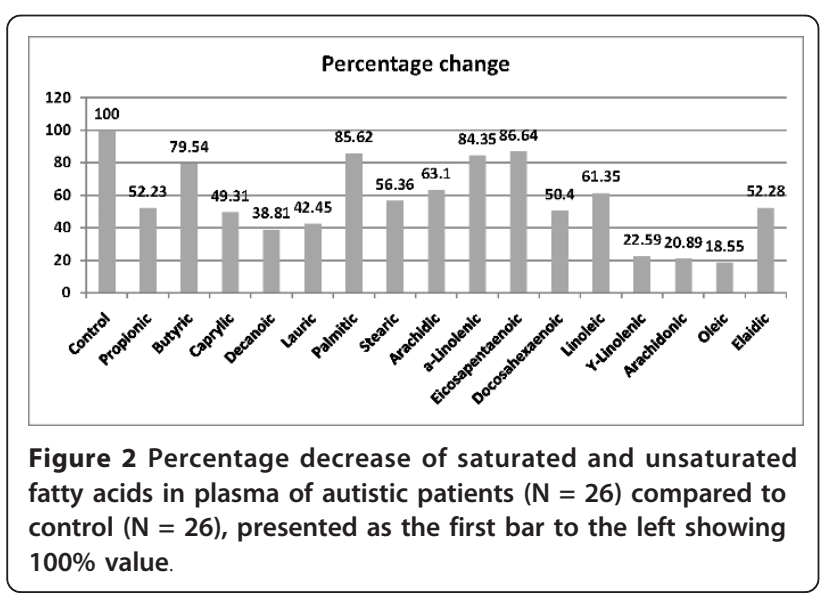

high level of plasma valeric acid observed in the present study could be easily explained and correlated to the $\mathrm{H}_{2} \mathrm{O}_{2}$ oxidative stress, impaired energy metabolism, and elevated plasma lactate previously recorded in Saudi autistic patients [26-29].

The recent work performed by MacFabe et al. (2007) [30] concerns the role of a panel of gut-borne factors in autism spectrum disorder through using a novel rodent model. The transport of propionate and butyrate across the blood brain barrier was previously ascertained [31-34]. These authors demonstrated that intracerebroventricular infusions of short chain fatty acids produced behavioral (hyperactive, preservative, social impairments), electrophysiological (seizure, caudate spiking), biochemical (increased oxidative stress, reduced glutathione, lipids) and neuropathological (innate neuroinflammation) changes in adult rats consistent with those seen in autism. References regarding the further development of this model from the behavioral to biochemical levels will further support this study findings and reduce the plausible argument that the lipid alterations are merely an epiphenomena caused by a poor diet and have nothing to do with autism pathophysiology per se. ${ }^{14} \mathrm{C}$ propionate and ${ }^{14} \mathrm{C}$ hydroxybutyrate were found to cross the blood-brain barrier with brain uptake indexes of 43.53 and $7.10 \%$, respectively. Transport of both of these substrates was saturable, with the values of transport $\mathrm{Km}$ being 2.03 and $6.54 \mathrm{mM}$, respectively. These differences in brain uptake indexes and transport $\mathrm{Km}$ values could be used to explain the obtained lower plasma propionate than butyrate recorded in the present study in autistic patients compared to healthy agematching controls. Since the lower the $\mathrm{Km}$, the higher the affinity of the transporters for the substrates, so an uptake index of $43.53 \%$ and a $\mathrm{km}$ value of 2.03 are enough to facilitate the penetration of propionate to the brain cell.

The observed results could confirm the previous work of MacFabe et al. (2007) [30] concerning the role of PPA in the etiopathology of autism and the possibility to use this short chain fatty acid to induce autism like behaviors and biochemical changes in animal model. Lower level of PPA in plasma of autistic patients could reflect the remarkable higher rate of uptake with brain.

There is growing interest in the roles of n-3 PUFA docosahexaenoic acid (DHA) and precursor eicosapentaenoic acid (EPA) in brain structure, function and mental health [35-37]. The longest chain n-3 DHA is the most abundant PUFA in brain membrane phospholipids indicative of its role in membrane fluidity and associated metabolic and neural activities. DHA is particularly concentrated at neural synapses, sites of neurotransmitter signalling. Omega-6 PUFA AA is also abundant in the brain reflecting a key role for brain structure and 


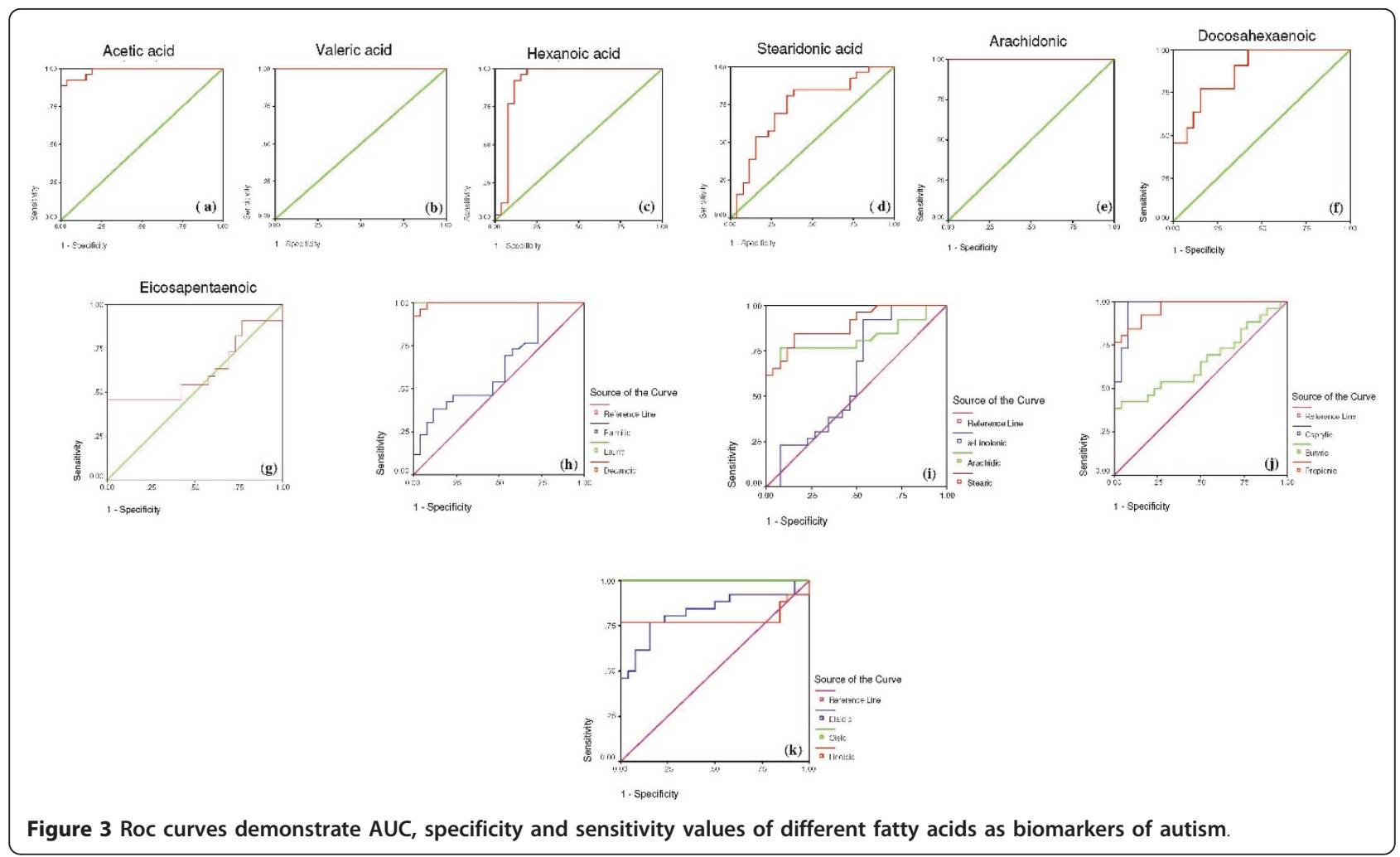

function. AA precursor, gamma-linolenic acid (GLA), and n-3 DHA precursor EPA are thought to be important for brain function via eicosanoid synthesis. EPA may be particularly important for production of eicosanoids with anti-inflammatory, anti-thrombotic, and vasodilatory properties [37].

PUFA have been proclaimed as critical for intellectual growth and development in the developing neonatal/ infant brain and in early childhood [38]. Given that brain development, particularly executive functioning (EF), continues throughout childhood [39,40], PUFA could also play an important role in cognitive function in older children. In addition, PUFA have been specifically associated with dopamine activity in the frontal lobes of the brain [41], which may impact directly on EF, and has been associated with Attention Deficit Hyperactivity Disorder (ADHD) [42].

Infants' brains are small and undeveloped at birth and must incorporate fatty acids and cholesterol from circulation to develop properly [43]. DHA plays a role in inhibition of neuronal apoptosis and in regulating neuronal excitability through GABA receptors $[9,10]$. Furthermore, there is evidence that developing brains obtain fatty acids transported through the blood, especially DHA [11].

The present investigation also indicated significantly lower levels of most PUFA (table 2 and figure 2), with exception of EPA which recorded non-significant lower concentration. This is in good agreement with the previous reports of Vancassel et al (2001) [44] who recorded decreased levels of the essential fatty acid DHA with normal levels of its omega-3 precursor in autism. Decreased DHA together with mild to moderate increases in lactate were observed in long chain FAO disorders [45]. Based on these observations, the lower level of DHA observed in the present study could be easily correlated to the previously reported increase of lactic acid in Saudi autistic patients [46].

In addition, lower level of AA recorded in the present work could find support through considering the work of Wiest et al. (2009) who attributed the impaired inflammatory responses seen in autistic patients to the diminished AA level in their plasma [47].

Diets rich in saturated fats may increase brain uptake of intact free fatty acids from the plasma through the blood brain barrier (BBB) [48], the BBB is not a barrier for fatty acids [49]. Patil and Chan (2005) study the role of FFAs in causing hyperphosphorylation of tau in primary rat cortical neurons [50]. The observed FFA-astrocyte-induced hyperphosphorylation of tau was reduced by co-treatment of neurons with $10 \mathrm{mM} \mathrm{N}$-acetyl cysteine (NAC), an antioxidant suggesting a central role of astroglia-mediated oxidative stress in the FFAinduced hyperphosphorylation of tau in neurons. Several 
studies have shown a relationship between elevated tissue $\mathrm{Pb}$ and oxidative stress biomarkers and fatty acid composition [51-54]. The impaired fatty acid profile recorded in the present study could be easily supporting the previous reports which demonstrate high plasma $\mathrm{Pb}$, elevated lipid peroxidation and low GSH levels in Saudi autistic patients compared to control [46].

It is proposed that saturated fatty acids (SFA) induce BBB dysfunction and delivery of toxic substances from blood- to-brain [55]. Moreover, Morgan (2009) [56] suggests that the underlying toxicity of SFA is a consequence of disturbances in protein processing and endoplasmic reticulum dysfunction, for example apoptotic induction. The present recognition of short chain fatty acids as biomarkers in Saudi autistic children could be supported through considering lipid-related biomarkers recorded in other neurological diseases. Miyake et al (2010) [54] observed positive relationship between cholesterol intake and the risk of Parkinson's disease (PD) but he recorded unaltered SFA levels in PD patients which is incompatible with the hypercholesterolemic effect of these acids. In addition, an emerging body of evidence is consistent with the hypothesis that dietary fats influence Alzheimer's disease (AD) risk, but less clear is the mechanisms by which this occurs. Accumulating evidence that dietary fats, specifically, chronic ingestion of saturated fats significantly influence cerebrovascular integrity and as a consequence altered amyloid beta $(\mathrm{A} \beta)$ kinetics across the BBB [55]. Regarding the role of saturated fatty acids in the etiology of autism, impaired mitochondrial FAO, elevated plasma very long chain saturated fatty acids (VLCFAs) was recorded as putative causal factors in the biochemistry, neuropathology, and gender bias in autism. This study is the first study which highlights the contribution of short chain fatty acids in the etiology of autism.

ROC curves are constructed by plotting the false positive rate (i.e. 100-specificity) against the true positive rate (i.e. sensitivity). These have been widely accepted as standard tools for evaluating the performance of diagnostic tests. The AUC is an overall summary of diagnostic accuracy, incorporating both components of accuracy, i.e., sensitivity and specificity, into a single measure. The AUC has been widely used as a quantitative index of the performance of a biomarker in a variety of applied fields; it is a simple and convenient overall measure of diagnostic test $[19,20]$. According to the presented ROC related data (tables 3 and 4 , figure 3 ), it could be easily concluded that impaired fatty acid profiles could be used as diagnostic biomarkers in Saudi autistic patients. Most of the measured fatty acids show a satisfactory level of specificity and sensitivity.

\section{Acknowledgements}

The authors would like to thank Shaik AL-Amodi Autism Research Chair and the parents of autistic children, without whom this work was not possible. This work was supported by King Abdul Aziz City for Science and Technology (KACST).

\section{Author details}

${ }^{1}$ Biochemistry Department, Science College, King Saud University, P.O Box 22452, Zip code 11495, Riyadh, Saudi Arabia. ${ }^{2}$ Autism Research and Treatment Center, King Saud University, P O Box 2925 Riyadh 11461 Saudi Arabia. ${ }^{3}$ Shaik AL-Amodi Autism Research Chair, King Saud University, P O Box 2925 Riyadh 11461 Saudi Arabia. ${ }^{4}$ Medicinal Chemistry Department, National Research Centre, P O Box 12622, Dokki, Cairo, Egypt. ${ }^{5}$ Department of Physiology, Faculty of Medicine, King Saud University, P O Box 2925 Riyadh 11461 Saudi Arabia.

\section{Authors' contributions}

AE designed the study and drafted the manuscript. ABB helped to draft the manuscript and performed the statistical analysis. LA provided samples and participated in the design of the study. All authors have read and approved the final manuscript.

\section{Competing interests}

The authors declare that they have no competing interests.

Received: 23 January 2011 Accepted: 21 April 2011

Published: 21 April 2011

\section{References}

1. Keller F, Persico AM: The neurobiological context of autism. Mol Neurobiol 2007, 28:1-22.

2. Beaud, et al: Is medical genetics neglecting epigenetics? Genet Med 2002, 4:399-402

3. Lord C, Risi S, Lambrecht L, Cook EH Jr, Leventhal BL, DiLavore PC, Pickles A, Rutter M: The autism diagnostic observations chedule-generic: a standard measure of social and communication deficits associated with the spectrum of autism. J Autism Dev Disord 2000, 30:205-23.

4. Volkmar FR, Lord C, Bailey A, Schultz RT, Klin A: Autism and pervasive developmental disorders. J Child Psychol Psychiatry 2005, 45:135-70.

5. Rutter M: Aetiology of autism: findings and questions. J Intellect Disabil Res 2005, 49:231-8.

6. Anderson SW, Bechara A, Damasio H, Tranel D, Damasio AR: Impairment of social and moral behavior related to early damage in human prefrontal cortex. Nat Neurosci 1999, 2:1032-37.

7. Jump DB: Minireview: The biochemistry of $n-3$ polyunsaturated fatty acids. J Biol Chem 2002, 277:8755-58

8. Muskiet FA, Fokkema MR, Schaafsma A, Boersma ER, Crawford MA: Is docosahexaenoic acid (DHA) essential? Lessons from DHA status regulation, our ancient diet, epidemiology and randomized controlled trials. J Nutr 2004, 134:183-6.

9. Nabekura J, Noguchi K, Witt MR, Nielson M, Akaike N: Functional modulation of human recombinant gamma-aminobutyric acid type a receptor by docosahexaenoic acid. J Biol Chem 1998, 273:11056-61.

10. Kim HY, Akbar M, Lau A, Edsall L: Inhibition of neuronal apoptosis by docosahexaenoic acid (22:6n-3). J Biol Chem 2000, 275:35215-35223.

11. Scott BL, Bazan NG: Membrane docosahexaenoate is supplied to the developing brain and retina by the liver. Proc Natl Acad Sci 1989, 86:2903-07.

12. Wanders RJ, Vreken $P$, den Boer ME, Wijburg FA, van Gennip AH, IJlst L: Disorders of mitochondrial fatty acyl-CoA beta-oxidation. J Inherit Metab Dis 1999, 22:442-87.

13. Wang SS, Fernhoff PM, Hannon WH, Khoury MJ: Medium chain acyl-CoA dehydrogenase deficiency human genome epidemiology review. Genet Med 1999, 1:332-339.

14. Roe $C R$, Ding $J H$ : Mitochondrial fatty acid oxidation disorders.Edited by: Scriver CR, Beaudet AL, Sly WS, Valle D. New York: McGraw-Hill; , eighth 2001:2297-2326, The metabolic and molecular basis of inherited disease.

15. Cox KB, Hamm DA, Millington DS, Matern D, Vockley J, Rinaldo P, Pinkert CA, Rhead WJ, Lindsey JR, Wood PA: Gestational, pathologic, and biochemical differences between very long-chain acyl-CoA 
dehydrogenase deficiency and longchain acyl-CoA dehydrogenase deficiency in the mouse. Hum Mol Genet 2001, 10:2069-77.

16. Bonnet $D$, Martin $D$, De Lonlay $P$, Villain E, Jouvet $P$, Rabier $D$, Brivet $M$, Saudubray JM: Arrhythmias and conduction defects as presenting symptoms of fatty acid oxidation disorders in children. Circulation 1999, 100:2248-2253.

17. Ziadeh R, Hoffman EP, Finegold DN, Hoop RC, Brackett JC, Strauss AW, Naylor EW: Medium-chain acyl-CoAdehydrogenase deficiency in Pennsylvania: neonatal screening shows high incidence and unexpected mutation frequencies. Pediatr Res 1995, 37:675-678.

18. Folch J, Lees M, Stanley GHS: A simple method for the isolation and purification of lipids from animal tissues. J Biol Chem 1957, 226:497-509.

19. Pepe MS: The statistical evaluation of medical tests for classification and prediction. 2003, 28, Woxford Statistical Science Series.

20. Zhou XH, Obuchowski N, McClish D: Statistical Methods in Diagnostic Medicine. Wiley, New York; 2002

21. Sharon P, Stenson WF: Metabolism of arachidonic acid in acetic acid colitis in rats. Similarity to human inflammatory bowel disease. Gastroenterology 1985, 88:55-63.

22. Fitzpatrick R, Bostwick JS, Renzetti M, Pendeleton RG, Decktor DL: Antiinflammatory effect of various drugs on acetic acid-induced colitis in rats. Agents Actions 1990, 30:393-402.

23. Yamada T, Mashall S, Specian RD, Grisham MB: A comparative analysis of two animal models of colitis in rats. Gastroenterology 1992, 102:1524-1534.

24. Zelitlin IJ, Norris AA: Animal model of colitis. In Mechanism of gastrointestinal inflammation. Edited by: Standstead A. BSG/SK 1983:70.

25. Sgaravatti AM, Rosa RB, Schuck PF, Ribeiro CA, Wannmacher CM, Wyse AT, Dutra-Filho CS, Wajner M: Inhibition of brain energy metabolism by the alpha-keto acids accumulating in maple syrup urine disease. Biochim Biophys Acta 2003, 1639:232-238.

26. Chauhan A, Chauhan V, Ted Brown W, Cohen I: Oxidative stress in autism: Increased lipid peroxidation and reduced serum levels of ceruloplasmin and transferrin - the antioxidant proteins. Life Sciences 2004, 7:2539-2549.

27. Al-Mosalim O, El-Ansary A, Attas O, Al-Ayadhi L: Selected enzymes related to energy metabolism in Saudi autistic children. Clin Biochem 2009, 42:949-957.

28. Al-Gadani Y, El-Ansary A, Attas O, Al-Ayadhi L: Oxidative stress and antioxidant status in Saudi autistic children. Clin Biochem 2009 42:1032-1040.

29. Ji L, Chauhan A, Ted Brown w, Chauhan V: Increased activities of $\mathrm{Na}+/ \mathrm{K}$ +-ATPase and $\mathrm{Ca} 2+/ \mathrm{Mg} 2+-$ ATPase in the frontal cortex and cerebellum of autistic individuals. Life Sciences 2009, 85:788-793.

30. MacFabe DF, Cain DP, Capote KR, Franklin AE, Hoffman JE, Boon F, Taylor AR, Kavaliers M, Ossenkopp KP: Neuroplogical effects of intraventricular propionic acid in rats: Possible role of short chain fatty acids on the pathogenesis and characteristics of autism spectrum disorders. Behav Brain Res 2007, 176:149-169.

31. Conn AR, Fell DI, Steele RD: Characterization of alpha-keto acid transport across blood-brain barrier in rats. Am J Physiol 1983, 245:253-260.

32. Shultz SR, MacFabe DF, Ossenkopp KP, Scratch S, Whelan J, Taylor R, Cain DP: Intracerebroventricular injection of propionic acid, an enteric bacterial metabolic end-product, impairs social behavior in the rat: implications for an animal model of autism. Neuropharmacology 2008, 54:901-911.

33. Thomas RH, Foley KA, Mepham JR, Tichenoff $L$, Possmayer F, MacFabe DF: Altered brain phospholipid and acylcarnitine profiles in propionic acid infused rodents: further development of a potential model of autism spectrum disorders. J Neurochem 2010, 113:515-29.

34. MacFabe DF, Cain NE, Boon F, Ossenkopp KP, Cain DP: Effects of the enteric bacterial metabolic product propionic acid on object-directed behavior, social behavior, cognition, and neuroinflammation in adolescent rats: Relevance to autism spectrum disorder. Behav Brain Res; 2011:217:47-54

35. Haag M: Essential fatty acids and the brain. Can J Psychiatry 2003, 48:195-203.

36. Young G, Conquer J: Omega-3 fatty acids and neuropsychiatric disorders. Reprod Nutr Dev 2005, 45:1-28.

37. Assisi A, Banzi R, Buonocore C, Capasso F, Di Muzio V, Michelacci F, Renzo D, Tafuri G, Trotta F, Vitocolonna M, Garattini S: Fish oil and mental health: The role of $n-3$ long chain polyunsaturated fatty acids in cognitive development and neurological disorders. Int Clin Psychopharmacol 2006, 21:319-336.

38. Broadhurst CL, Wang Y, Crawford MA, Cunnane SC, Parkington JE, Schmidt WF: Brain-specific lipids from marine, lacustrine, or terrestrial food resources: potential impact on early African Homo sapiens. Comp Biochem Physiol 2002, 131:653-73.

39. Thatcher RW: Maturation of the human frontal lobes. Physiological evidence for staging. Dev Neuropsychol 1991, 7:397-419.

40. Toga AW, Thompson PM, Sowell ER: Mapping brain maturation. Trends Neurosci 2006, 29:148-159.

41. Chalon S, Vancassel S, Zimmer L, Guilloteau D, Durand G: Polyunsaturated fatty acids and cerebral function: focus on monoaminergic neurotransmission. Lipids; 2001:36:937-44.

42. Biederman J, Petty CR, Monuteaux MC, Fried R, Byrne D, Mirto T, Spencer T, Wilens TE, Faraone SV: Adult psychiatric outcomes of girls with attention deficit hyperactivity disorder: 11-year follow-up in a longitudinal casecontrol study. Am J Psychiatry 2010, 167:409-17.

43. Anderson GJ, Tso PS, Connor WE: Incorporation of chylomicron fatty acids into the developing rat brain. J Clin Invest 1994, 93:2764-2767.

44. Vancassel S, Durand G, Barthelemy C, Lejeune B, Martineau J, Guilloteau D, Andrès C, Chalon S: Plasma fatty acid levels in autistic children. Prostaglandins Leukotr Essent Fatty Acids 2001, 65:1-7.

45. Infante JP, Huszagh VA: Secondary carnitine deficiency and impaired docosahexaenoic (22:6 $n \_3$ ) acid synthesis: a common denominator in thepathophysiology of diseases of oxidative phosphorylation and betaoxidation. FEBS Lett 2000, 468:1-5.

46. El-Ansary A, Al-Daihan S, Al-Dbass A, Al-Ayadhi L: Measurement of selected ions related to oxidative stress and energy metabolism in Saudi autistic children. Clin Biochem 2010, 43:63-70.

47. Wiest MM, German JB, Harvey DJ, Watkins SM, Hertz-Picciotto I: Plasma fatty acid profiles in autism: A case-control study. Prostaglandins Leukotr Essent Fatty Acids 2009, 80:221-227.

48. Wang SW, Wang M, Grossman BM, Martin RJ: Effects of dietary fat on food intake and brain uptake and oxidation of fatty acids. Physiol Behav 1994, 56:517-22.

49. Dhopeshwarkar GA, Mead JF: Uptake and transport of fatty acids into the brain and role of the blood-brain barrier system. Adv Lipid Res 1973, 11:109-142.

50. Patil S, Chan C: Palmitic and stearic fatty acids induce Alzheimer-like hyperphosphorylation of tau in primary rat cortical neurons. Neurosci Lett 2005, 384:288-93.

51. Donaldson WE, Knowles SO: Is lead toxicosis a reflection of altered fatty acid composition of membranes? Comp Biochem Physiol C Toxicol Pharmacol 1993, 104:377-379.

52. Gurer $\mathrm{H}$, Ercal N: Can antioxidants be beneficial in the treatment of lead poisoning? Free Radic Biol Med 2000, 29:927-45.

53. Hsu PC, Guo YL: Antioxidant nutrients and lead toxicity. Toxicology 2002, 180:33-44.

54. Miyake Y, Sasaki S, Tanaka K, Fukushima W, Kiyohara C, Tsuboi Y, Yamada T, Oeda T, Miki T, Kawamura N, Sakae N, Fukuyama H, Hirota Y, Nagai M: Dietary fat intake and risk of Parkinson's disease: A case-control study in Japan. J Neurol Sci 2010, 288:117-122.

55. Takechi R, Galloway S, Pallebage-Gamarallage MMS, Lam V, Mamo JCL: Dietary fats, cerebrovasculature integrity and Alzheimer's disease risk. Prog Lipid 2010, 49:159-70.

56. Morgan NG: Fatty acids and beta-cell toxicity. Curr Opin Clin Nutr Metab Care 2009, 12:117-22.

doi:10.1186/1476-511X-10-62

Cite this article as: El-Ansary et al:: Plasma fatty acids as diagnostic markers in autistic patients from Saudi Arabia. Lipids in Health and Disease 2011 10:62. 